\title{
Prof. Thomas Anthony D'Amico: looking beyond the boundary
}

Submitted Nov 09, 2018. Accepted for publication Nov 14, 2018.

doi: $10.21037 /$ jtd.2018.11.142

View this article at: http://dx.doi.org/10.21037/jtd.2018.11.142

\section{Editor's note}

The AATS Focus (Focus on thoracic surgery: lung cancer and esophageal cancer) Conference 2018 was held in Guangzhou on November $3^{\text {rd }}$ and $4^{\text {th }}$. More than 40 scholars from home and abroad gathered together to share the latest cutting-edge technology in thoracic surgery with the conference attendees. After the meeting, we were honored to invite Professor Thomas A. D'Amico, one of the chairmen of the meeting, to be interviewed.

\section{Expert introduction}

Dr. Thomas A. D'Amico (Figure 1) is a graduate of Harvard University (BA) and the College of Physicians \& Surgeons of Columbia University (MD). He received training in general surgery and thoracic surgery at Duke University Medical Center. After completing a fellowship in thoracic surgical oncology at the Memorial Sloan-Kettering Cancer Center, Dr. D'Amico joined the faculty at Duke University Medical Center in 1996. He is currently the Gary Hock Endowed Professor, Chief of General Thoracic Surgery, Director of the Training Program in Thoracic Surgery, and Chief Medical Officer and Director of the Thoracic Oncology Program of the Duke Cancer Institute.

As Director of the Thoracic Oncology Program of the Duke Cancer Institute, Dr. D'Amico supervises the clinical and research programs in lung cancer and esophageal cancer. He is involved in improving safety and quality in patient care, as a member of the Duke Quality and Safety Committee and the Perioperative Executive Committee.

Dr. D'Amico is an associate editor for the Fournal of Thoracic and Cardiovascular Surgery and serves on several other editorial boards. He is in leadership positions in the American Association for Thoracic Surgery, the Residency Review Committee for Thoracic Surgery, the Society of Thoracic Surgeons, and the International Association for the Study of Lung Cancer. Finally, he is the active in the National Comprehensive Cancer Network (NCCN), as a member of NCCN Board of Directors and Guidelines Steering Committee, the Chair of the Quality and Outcomes Committee, as well as a member of the Lung Cancer

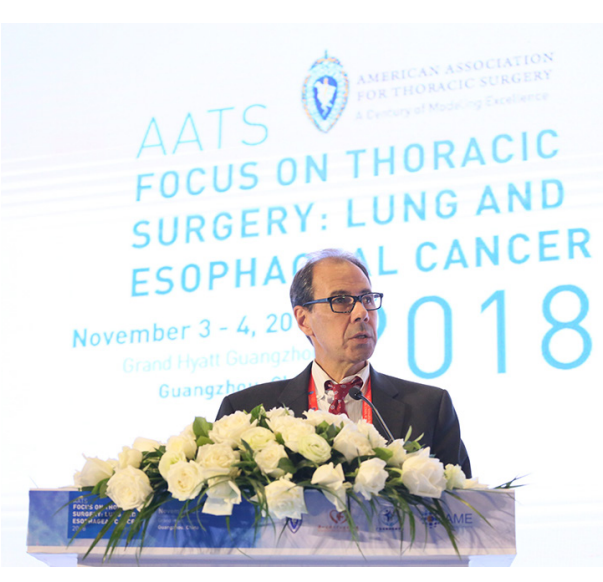

Figure 1 Prof. Thomas Anthony D'Amico.

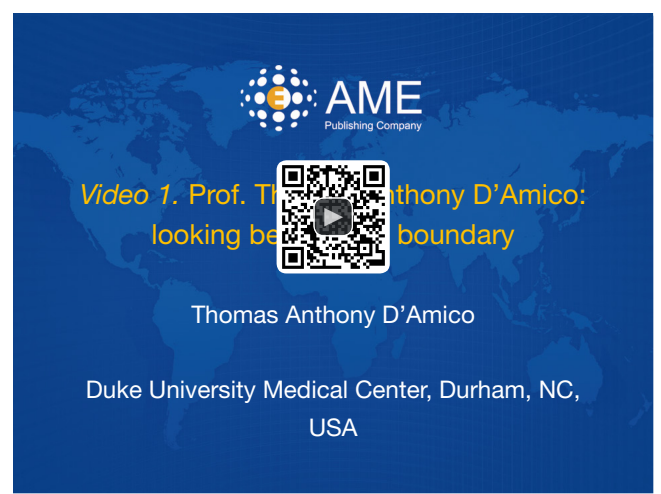

Figure 2 Interview with Prof. Thomas Anthony D'Amico: looking beyond the boundary (1).

Available online: http://www.asvide.com/article/view/29199

Guidelines Committee and co-chair of the Esophageal Cancer Guidelines Committee.

\section{Interview (Figure 2)}

FTD: As the program co-director of AATS Focus, what is your expectation of this congress?

Prof. D'Amico: As the program director of AATS Focus 


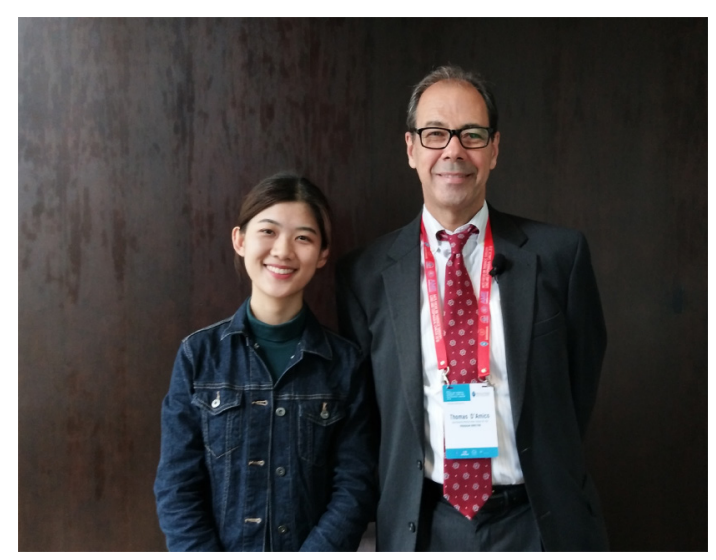

Figure 3 Photo with Prof. D'Amico after the interview.

China, my expectation is that we produce the best possible teaching experience that includes the experience and influence of faculty, internationally from North America, from Europe, and from Asia. The second focus of the teaching experience is to create better relationships between surgeons across the globe, so we can fellowship together. The third goal is that we increase the ability of the AATS to improve education worldwide today.

\section{FTD: Could you please share the take-home message of your speech on thoracoscopic sleeve resection and pneumonectomy?}

Prof. D'Amico: The focus of my presentation on thoracoscopic sleeve resection and pneumonectomy is to demonstrate how minimally invasive techniques are acceptable for even the most invasive cancers, and even the most difficult procedures. It might not be that every single patient that requires a sleeve resection or pneumonectomy should be operated on the minimally invasively, but it teaches us to look beyond the boundary on how we talk about minimally-based surgery and use the scope of our abilities throughout all possible opportunities.

\section{FTD: As we know, you have been active in "Teaching Innovative Thoracic Surgery in China". What do you think of the current development situation of thoracic surgery in China?}

Prof. D'Amico: I have been teaching innovative thoracic surgery in China for approximately 10 years now. I visited more than 25 cities on countless trips and I count each of these. I am amazed at how thoracic surgery here has improved over the years. These areas are better developed than some cities in Europe and even North America. Chinese surgeons have a hunger to do the best possible operation for their patients and challenge themselves to be the best surgeons they can be. So, whether it's in the AATS Focus Meetings, Training, National Meetings, Meeting the Professors or operating with my Chinese colleagues, I continue to be impressed at the progress that Chinese surgeons have made over the years and I just want to continue to be better.

\section{fTD: What's the hottest issue in thoracic surgery? Would} you like to tell us the current status of your recent research?

Prof. D'Amico: I think if I were to choose one issue going forward in thoracic surgery to focus on as a young thoracic surgeon, I would focus on how immunotherapy can be best used for surgical patients. Research could include immunotherapy preoperatively for lung cancer, immunotherapy postoperatively for lung cancer, preoperatively for esophageal cancer and of course postoperatively for esophageal cancer. I think immunotherapy is a technique that has the best ability in the next few decades to improve survival rate in both lung cancer and esophageal cancer. I think surgeons should want to be part of this research.

\section{FTD: What motivates you to pursue excellence in medicine? And what is your advice to young researchers?}

Prof. D'Amico: My goal for success in medicine has been based on the expectation that my mentors had for me. They saw something in me and they were willing to spend time with me to improve my path, to teach me that I could be what I wanted to be. My advice for young surgeons would be two-fold. Firstly, find the mentor that expects more from you than you expect from yourself, and do everything you can to follow that mentorship. Secondly, ask yourself: what do you want to be in 10 years, where would you like to be and what would you like to get accomplished? Try to drive the most direct route between now and that picture of yourself in 10 years (Figure 3).

\section{Acknowledgements}

None. 


\section{Footnote}

Conflicts of Interest: The author has no conflicts of interest to declare.

\section{References}

1. Fan LH. Prof. Thomas Anthony D'Amico: looking beyond

Cite this article as: Fan LH. Prof. Thomas Anthony D'Amico: looking beyond the boundary. J Thorac Dis 2018;10(12):E843E845. doi: 10.21037/jtd.2018.11.142 the boundary. Asvide 2018;5:937. Available online: http:// www.asvide.com/article/view/29199

(Science Editor: Li-Hua Fan, JTD, jtd@amepc.org)

(English Language Editor: John Ayric Gray, AME Publishing Company) 